\title{
Evaluation of the Physical Properties of Unbound Base Layer Containing Recycled Aggregates
}

\author{
H. Taherkhani
}

\begin{abstract}
Construction industry is among the major contributor to the production of solid wastes, which have become a main problem of societies in present days. Asphalt and cement concrete are among the main engineering materials which are wasted in vast quantities every year due to the reconstruction and demolition of highways and buildings. Recycling of these materials would be an efficient measure for protection of environment and preservation of natural resources. In this research, the viability of using crushed waste asphalt and cement concrete as a replacement of primary aggregate in unbound base layer of flexible pavements has been investigated. Different portions of the natural aggregate have been replaced with the recycled materials and the physical properties of each mixture have been investigated. The physical properties including sand equivalent, toughness, water absorption, density, soundness and compaction have been evaluated for the mixtures. The results show that, they have potential to be used in unbound base layer. Inclusion of any amount of recycled cement concrete in unbound aggregate results in a mixture which satisfy the minimum required sand equivalent, toughness and soundness for unbound base.
\end{abstract}

Index Terms-Recycled asphalt concrete, recycled cement concrete, unbound base.

\section{INTRODUCTION}

The extensive amount of solid waste materials has become a serious environmental problem of present days life. Therefore, in order to protect the environment and save the economy, managing the solid waste materials through their recycling and reusing has attracted the attention of researchers and engineers. One of the industries, with the major contribution into the generation of waste materials and consumption of energy and natural resources, is the construction industry. It consumes about $40 \%$ of total consumed energy and about $50 \%$ of natural resources, and produces $50 \%$ of total waste materials [1]. The large quantities of construction and demolition wastes (CDW) have been generated from increasing construction, maintenance and demolition activities, and infrastructure development projects. The huge amount of CDW materials causes harmful effects on the environment if they are not properly managed. The environmental problems include diminishing landfill spaces due to incremental quantities of disposed wastes, depleting construction materials, raising the contamination from landfills that lead to serious negative health effects, damage to the environment and the increase of energy consumption for transportation and manufacturing new materials instead of those dumped in landfills. CDW,

Manscript received May 12, 2014; revised July 8, 2014.

H. Taherkhani is with University of Zanjan, Zanjan, Iran (e-mail: taherkhani.hasan@znu.ac.ir). also contribute into the phenomenon of global warming. There is increased pressure and incentive to recover the CDW materials in secondary applications. CDW materials have been significantly recycled since the end of the Second World War [2]. The current practice in Iran and many other developing countries is disposing the CDW materials and occupying the valuable landfills.

Reclaimed asphalt and cement concrete constitute the main fraction of the $\mathrm{CDW}$ materials. Reclaimed concrete materials (RCM), also known as crushed concrete, is produced primary from demolition of existing buildings, concrete pavements, bridge structures, curb and gutter. In US, Concrete comprises $67 \%$ of total construction waste materials [3]. Reclaimed asphalt pavement (RAP) is bituminous concrete materials removed from pavement undergoing reconstruction or resurfacing. Reclaiming the asphaltic concrete may involve either cold milling a portion of the existing bituminous concrete pavement, or its full depth removal and crushing. One of the applications for the RAP and RCM is in Portland cement concrete production as a replacement of virgin aggregates. In UK, $10 \%$ of the total consumed aggregate is produced from recycled concrete [4]. However, the replacement ratio of recycled aggregates in concrete is limited to a certain value [5]. Huang et al. [6], [7], investigated the effects of using RAP in cement concrete by replacing the coarse and fraction of aggregate with the reclaimed asphalt, and found that the mixtures containing recycled aggregate have a lower tensile and compressive strength than the mixture containing virgin aggregates. However, the mixtures containing recycled asphalt concrete showed to have a higher toughness.

Highways are built in several layers of surface, base and sometimes sub-base. The surface layer is made of Portland cement or asphalt concrete. The base and sub-base layers are usually made of bound or unbound aggregate. Aggregate consists of hard, graduated fragments of inert mineral materials including sand gravel, crushed stones, rock dust or powder. As the highway construction requires large volumes of materials, it has been one of the major applications for using CDW materials. The use of CDW materials in highway construction can preserve natural resources, and reduce environmental pollution as otherwise virgin materials should be taken from natural resources, and their processing, production and transportation consumes energy. The CDW materials can be used in different layers of pavement structure, such as base, sub-base and surface course. The viability of using CDW materials, as bound materials, in highway construction has been investigated in different studies [5], [8]-[14]. Another application for the recycled materials is in unbound base and sub-base layers of pavement. In Britain, O’Mahony and Milligan studied the 
viability of using crushed concrete and demolition wastes as sub-base coarse aggregate [15]. CBR experiments were conducted and the behavior of the recycled materials was compared with the behavior of limestone. The results showed that CBR of crushed concrete was similar to that of the natural aggregate. Bennert et al. [16] analyzed the performance of recycled concrete aggregate in base and subbase applications. The authors concluded that a blended mixture of $25 \%$ of recycled concrete aggregate with $75 \%$ of natural aggregate would obtain the same resilient response and permanent deformation properties as a dense-graded aggregate base coarse, currently used in base and sub-base layers. Molenaar and van Niekerk [8] studied the influence of composition, gradation and degree of compaction on mechanical characteristics of crushed concrete and crushed masonry in the Netherlands. The results demonstrated that although the composition and gradation have an influence on the mechanical characteristics of the recycled materials, the degree of compaction is clearly the most important factor.

The major fraction of the waste asphalt and cement concrete materials in Iran are disposed, which has made environmental problems. A small fraction of the reclaimed asphalt is used for paving the highway shoulders. On the other hand, the base layer of most highways in Iran is made of unbound virgin aggregate, which are obtained from natural resources of aggregate after required processing. In this research, the viability of replacing the virgin aggregate of unbound base layer with the recycled asphalt and cement concrete is investigated.

\section{EXPERIMENTAL INVESTIGATION}

\section{A. Materials}

The materials used in this research include natural primary aggregates and recycled aggregates produced from crushing waste cement and asphalt concrete. The calcareous natural aggregates were collected in three different sizes of coarse (larger than $4.75 \mathrm{~mm}$ ), middle ( 2 to $4.75 \mathrm{~mm}$ ) and fines (smaller than $2 \mathrm{~mm}$ ) from the deposits of an aggregate production plant in Mashhad city in Iran. After determination of the gradation of each fraction, and choosing the mixture gradation from specifications, the percentage of each fraction in the mixture was determined. The recycled asphalt concrete aggregate was obtained from the waste milled asphalt concrete from the surface layer of a pavement in Khorasan Province. The waste asphalt concrete was first placed in an oven to be softened. Then the large pieces were crushed into finer particles using a plastic hammer. The recycled cement concrete aggregate was produced by crushing waste laboratory specimens using a laboratory jaw crusher and a steel hammer. The recycled aggregates were separated in three different sizes of coarse particles (larger than 4.75), middle size particles (between 4.75 and $2 \mathrm{~mm}$ ) and fine particles (smaller than $2 \mathrm{~mm}$ ). Gradation test was conducted on each fraction, and using the standard gradation limits, the percentage of each fraction for mixing was determined. The physical properties of the natural and recycled aggregates were determined by conducting standard tests on the specimens of the aggregates. Table I shows the measured properties, the standard of the tests and the results for each aggregate. As can be seen, the bulk density of the fine and coarse fraction of the recycled aggregates is lower than that of the natural aggregate, with the lowest density for the recycled cement concrete aggregate. It is also evident that, although the water absorption of the recycled asphalt concrete is slightly lower than that of the natural aggregate, which is due to the asphalt coat of the particles, the water absorption of the fine and coarse fraction of the recycled cement concrete aggregate is considerably higher than those of the recycled asphalt and natural aggregates. The sand equivalent test results also show that the recycled concrete has a higher dust like particles than the others. In terms of toughness, which is an indication of resistance against impacts, the natural aggregate perform better than the recycled cement and asphalt concrete. However, the soundness of the recycled aggregates is not significantly different from that of the natural aggregate. The physical properties of the mixtures containing different portions of the recycled and natural aggregates are discussed in the following sections.

\section{B. Testing Program}

In order to evaluate the possibility of using recycled asphalt and cement concrete in unbound base, as a replacement of the natural aggregate, different percentages of the natural aggregate were replaced with the recycled asphalt and cement concrete aggregate. By this, 7 different types of mixture were produced. The mixture containing $100 \%$ of natural aggregate was considered as the control mixture, and 6 different mixtures were made by replacing 20,50 and $75 \%$ of the natural aggregate with the recycled aggregates. The replaced particles include the coarse, middle size and fines, each at the same ratio. Table 2 shows the denotations of the mixtures to be used in this paper and the percentages of each constituent. After production of the mixtures, using a standard gradation for unbound base from the specifications, the gradation of each mixture was controlled to be between the standard limits. Table 3 shows the standard gradation and the gradations of the mixtures used in this research. On each mixture, different tests, including measuring the density and absorption of fine and coarse aggregate, toughness of coarse and sand equivalent of fine aggregate, soundness in sodium sulfate and freezing and thawing, compaction and strength of compacted mixture were conducted. Table IV shows the tests and the standards according which the tests have been conducted on the mixtures. In order to determine the effect of compaction level on the strength, the CBR test was conducted on the specimens of the mixtures compacted at different impacts of 10,30 and 56 .

\section{TESTS RESUlts AND Discussions}

\section{A. Sand Equivalent Tests Results}

Exceeding the clay-like particles in an unbound base from a certain amount leads to impairing the performance of the layer under traffic loading. Sand equivalent (S.E.) is used as a criterion for the cleanness of the fine fraction of an aggregate and the amount of clay-like or fine dust particles. The higher S.E. is an indication of higher content of the 
desirable coarse particles in the mixed aggregate and less contamination by the plastic fines. Figure 1 shows the sand equivalent of the control mixture and the mixtures containing recycled aggregates. As can be seen, except the mixture containing $20 \%$ of recycled asphalt, the rest of the mixtures have a lower sand equivalent than the control mixture. The figure also shows that the sand equivalent decreases with increasing the percentage of the recycled aggregate in the mixture. This is attributed to the fact that the control aggregate have been washed in aggregate production plant and the recycled aggregate have been incorporated in the mixtures without washing away the dusts. Therefore, it is recommended that the recycled aggregates be washed before using in unbound base layer. The results also show that, in general, the mixtures containing recycled asphalt concrete aggregate have a higher sand equivalent than the mixtures containing recycled cement concrete. This is attributed to the less resistance of the recycled cement concrete against wear and the existence of a higher amount of dust on the surface of recycled cement concrete particles. According to the requirements of the specifications for unbound base, the minimum sand equivalent is 40 , which is satisfied by all the mixtures, indicating that the mixtures containing recycled aggregates meet this requirement.

TABLE I: PRPOPERTIES OF THE AGGREGATES USED IN THIS RESEARCH

\begin{tabular}{|c|c|c|c|c|}
\hline Aggregate type & $\begin{array}{c}\text { Recycled asphalt } \\
\text { concrete }\end{array}$ & $\begin{array}{c}\text { Recycled cement } \\
\text { concrete }\end{array}$ & $\begin{array}{c}\text { Natural } \\
\text { aggregate }\end{array}$ & Standard \\
\hline Properties & - & - & 14 & ASTM D4318 \\
\hline Liquid Limit & - & 2.195 & 2.675 & ASTM D854-92 \\
\hline $\begin{array}{c}\text { Plastic Limit } \\
\text { coarse aggregate }\end{array}$ & 2.305 & 2.357 & 2.632 & ASTM C128-12 \\
\hline $\begin{array}{c}\text { Bulk density of fine } \\
\text { aggregate }\end{array}$ & 2.451 & 7.984 & 0.78 & ASTM D854-92 \\
\hline $\begin{array}{c}\text { Absorption of } \\
\text { coarse aggregate }\end{array}$ & 0.602 & 5.911 & 1.488 & ASM C128-12 \\
\hline $\begin{array}{c}\text { Absorption of fine } \\
\text { aggregate }\end{array}$ & 1.463 & 68.33 & 73 & ASTM-D2419 \\
\hline $\begin{array}{c}\text { Cleanness of fine } \\
\text { aggregate }\end{array}$ & 74.66 & 33.44 & 24.8 & ASTM-C131 \\
\hline Toughness & 36.7 & 0.35 & 0.6 & AASHTO T103 \\
\hline $\begin{array}{c}\text { Soundness in } \\
\text { freezing and } \\
\text { thawing }\end{array}$ & 0.58 & 0.6 & 0.46 & AASHTO T104 \\
\hline $\begin{array}{c}\text { Soundness in } \\
\text { sodium sulfate }\end{array}$ & 0.6 & - & & ASTM \\
\hline
\end{tabular}

TABLE II: THE MIXTURES USED IN THIS RESEARCH

\begin{tabular}{|c|c|c|}
\hline Name of mixture & $\begin{array}{l}\text { Percentage of replacement with } \\
\text { recycled aggregates } \%\end{array}$ & Remarks \\
\hline B100 & 0 & control mixture \\
\hline $\mathrm{B} 80-\mathrm{C} 20$ & 20 & \multirow{3}{*}{$\begin{array}{l}\text { Mixtures containing recycled cement } \\
\text { concrete }\end{array}$} \\
\hline $\mathrm{B} 50-\mathrm{C} 50$ & 50 & \\
\hline $\mathrm{B} 25-\mathrm{C} 75$ & 75 & \\
\hline B80-A20 & 20 & \multirow{3}{*}{$\begin{array}{l}\text { Mixtures containing recycled asphalt } \\
\text { concrete }\end{array}$} \\
\hline B50-A50 & 50 & \\
\hline B25-A75 & 75 & \\
\hline
\end{tabular}

TABLE III: GRADATION OF THE MIXTURES USED IN THIS RESEARCH

\begin{tabular}{|l|l|l|l|l|l|l|l|l|}
\hline $\begin{array}{l}\text { Sieve size } \\
(\mathrm{mm})\end{array}$ & B100 & B80-C20 & B50-C50 & B25-C75 & B80-A20 & B50-A50 & B25-A75 & $\begin{array}{l}\text { Standard } \\
\text { limits }\end{array}$ \\
\hline 19 & 86.5 & 84.82 & 78.49 & 69.95 & 91.96 & 78.49 & 69.95 \\
\hline 9.5 & 62 & 61.54 & 63.1 & 48.25 & 65.38 & 63.1 & $60-80$ \\
\hline 4.75 & 49.22 & 48.86 & 51.7 & 36.13 & 49.18 & 51.7 & 48.25 & $30-65$ \\
\hline 2 & 33.7 & 29.95 & 28 & 21.88 & 31.32 & 28 & 21.88 & 13 \\
\hline 0.425 & 14.12 & 11.7 & 9.8 & 9.23 & 11.11 & 9.8 & 9.73 & $8-20$ \\
\hline 0.075 & 6.25 & 5.23 & 4.2 & 5.5 & 4.6 & 4.2 & 5.5 & $2-8$ \\
\hline
\end{tabular}

TABLE IV: STANDARD TESTS CONDUCTED ON THE MIXTURES

\begin{tabular}{|c|c|}
\hline Tests & Standard \\
\hline Density and absorption of coarse aggregate & ASTM D854-92 \\
\hline Density and absorption of fine aggregate & ASTM C128-12 \\
\hline Compaction & AASHTO T180 \\
\hline Los Angeles Abrasion test & ASTM C131 \\
\hline Sand Equivalent test & ASTM D2419 \\
\hline Sulfate soundness & AASHTO T104 \\
\hline Freezing and thawing test & AASHTO T103 \\
\hline CBR & AASHTO T193 \\
\hline
\end{tabular}




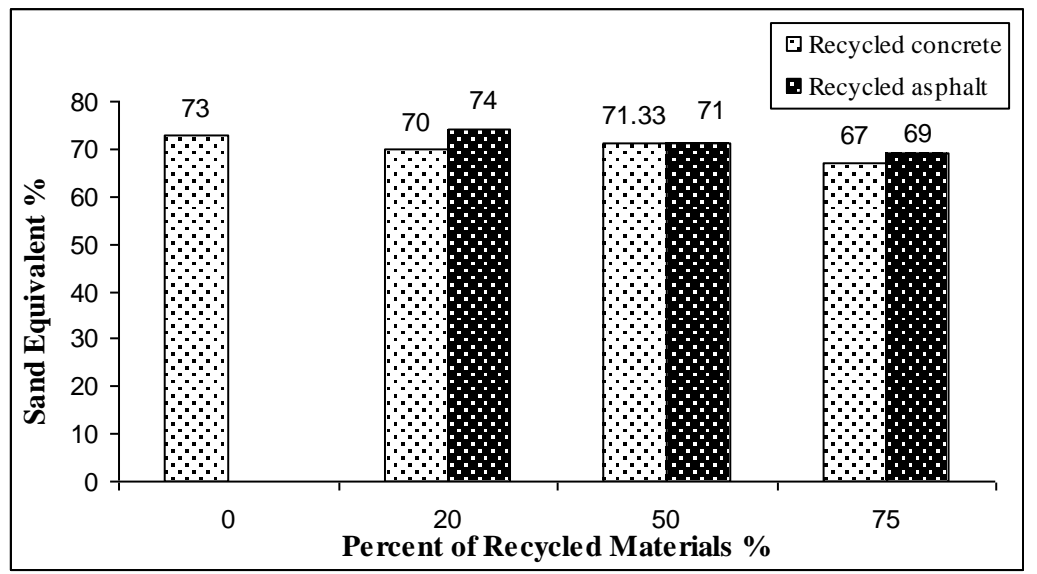

Fig. 1. Sand equivalent of the mixtures.

\section{B. Los Angeles Abrasion Tests Results}

In order to evaluate the resistance of the coarse fraction of the mixtures against impacts and abrasion, Los Angeles abrasion test was conducted on the mixtures according to ASTM C131 standard method. Fig. 2 shows the results of the Los Angeles tests, where the L.A. abrasion loss value in percentage has been shown for the mixtures. As can be seen, the mixtures containing recycled aggregates have a higher abrasion value than the control mixture, and the resistance against impact and abrasion decreases with increasing the percentage of recycled aggregate in the mixtures. This is partly attributed to the source of the aggregates used in the asphalt and cement concrete, and to the weakened particles obtained from crushing the cement concrete and milling the asphalt concrete. It can also be seen that the mixtures containing recycled asphalt concrete have a higher abrasion value than the mixtures containing recycled cement concrete. This is attributed to the source of the aggregate used for the asphalt and cement concrete. According to the requirements of specifications, the maximum abrasion value of unbound base is limited to 40 , which is satisfied by all the mixtures, indicating that the use of recycled aggregates in unbound base will not cause any problem related to the resistance and abrasion.

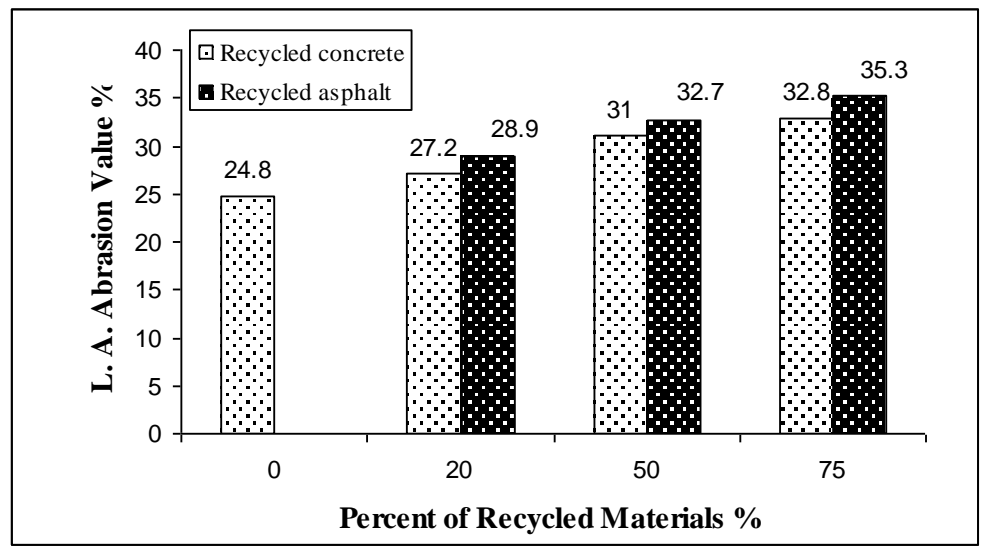

Fig. 2. Loss in Los Angeles test.

\section{Density and Absorption Tests Results}

Fig. 3 and Fig. 4 show, respectively, the bulk density of coarse and fine aggregate for the mixtures. As can be seen, the density of coarse and fine aggregate decreases with increasing the percentage of recycled aggregates in the mixtures. This is due to the lower density of the recycled aggregates than the natural aggregates, as seen in Table I. It can also be seen that the density of the mixtures containing recycled asphalt concrete is higher than the mixtures containing recycled cement concrete, which could be due to the lower density of the aggregates used in the concrete than those used in the asphalt concrete and also the higher porosity of the recycled cement concrete particles. However, the difference between the fine aggregates is less than the difference between coarse aggregates of the mixtures, which is because of the lower difference between the fine aggregate of recycled asphalt and cement concrete than the difference between the coarse aggregate of the recycled aggregates, as shown in Table I. Although the density is not an effective factor in performance of the unbound base, however, the lower density, results in a lower cost for transportation in construction operations.

Fig. 5 and 6 show, respectively, the water absorption of the coarse and fine aggregates of the mixtures. As can be seen, due to the higher absorption of the recycled cement concrete aggregate, which is also shown in Table I, the absorption of the fine and coarse aggregate increases with increasing the percentage of the recycled cement concrete in the mixtures. However, the water absorption of the mixtures containing recycled asphalt concrete is not significantly different from that of the control mixture. Although, the high water absorption influence the durability of unbound aggregate; however, there is not any requirement in the specifications for the water absorption of fine and coarse 
aggregates of unbound base materials. Therefore, this property is not effective in the acceptance of the mixtures

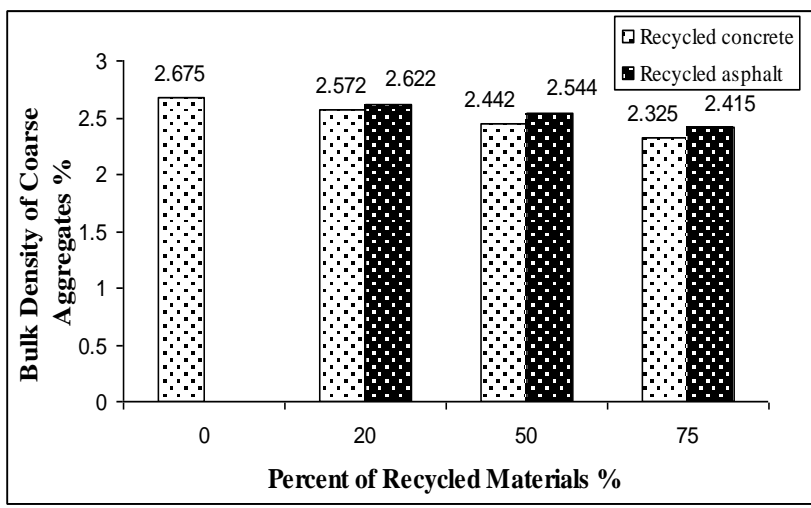

Fig. 3. Bulk density of coarse aggregate of the mixtures.

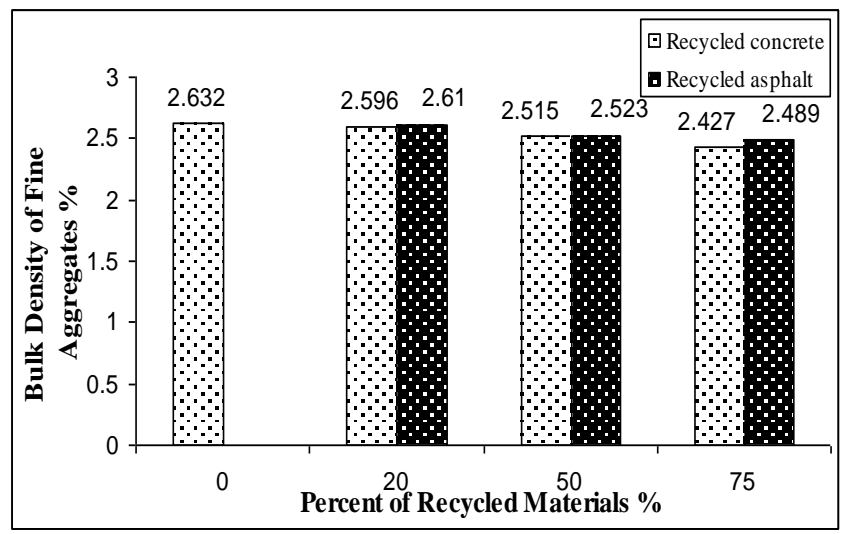

Fig. 4. Bulk density of fine aggregate of the mixtures.

\section{Soundness Tests Results}

The aggregates used in unbound base layer are required to resist the detrimental effects of environmental conditions which the materials are exposed. Unbound base layer is placed immediately beneath the surface layer and may expose to the moisture infiltrated from the surface through the cracks in the surface layer. In addition, due to the proximity of the materials to the surface of the pavement, they are vulnerable to the freezing and thawing cycles and exposing to the cycles of wetting and drying. Using of inferior materials in unbound base results in their disintegration under cycles of wetting and drying and freezing and thawing, leading to the change in their gradation impeding to perform appropriately in resisting the stresses and distributing it to the underlying layers and draining the infiltrated water. Therefore, they are required to be evaluated for the resistance against the detrimental effects of environmental conditions. In this research, the mixtures were evaluated by conducting sodium sulfate and freezing and thawing soundness tests on the fine and coarse aggregate. Table $\mathrm{V}$ shows the results of the tests, where the percent loss of the specimens after a certain number of cycles is shown for the mixtures. As can be seen, the mixtures containing recycled aggregates perform better than the control mixture in sodium sulfate soundness test. However, there is not a certain trend for the freezing and thawing soundness test results. The maximum percent loss of the aggregate for unbound base in sodium sulfate soundness test is limited to $12 \%$ in the specifications. In containing recycled aggregates.

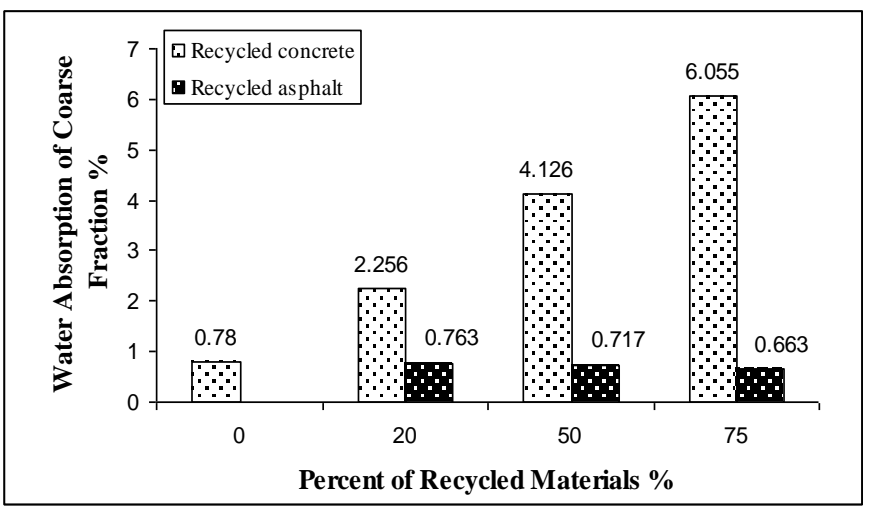

Fig. 5. Water absorption of coarse aggregate of the mixtures.

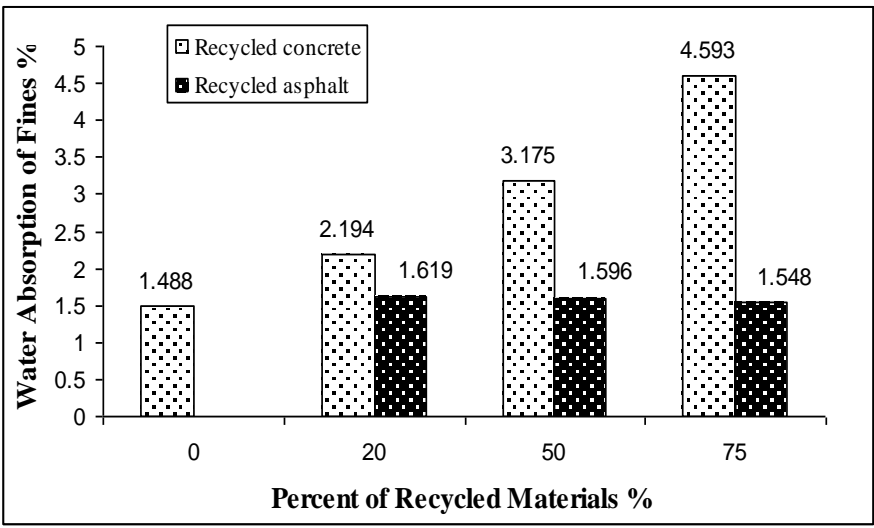

Fig. 6. Water absorption of fine aggregate of the mixtures.

Iranian specifications, there is not any limitation on the percent loss in freezing and thawing soundness test for the unbound base, however, in some countries, the maximum percent loss under 16 cycles of freezing and thawing is limited to $18 \%$. Therefore, the results show that the mixtures containing the recycled aggregates have a percent loss much less than the maximum limited by specifications.

\section{E. Compaction Tests Results}

The compaction test was conducted on the mixtures to determine the maximum dry density and the optimum moisture. Fig. 7 shows the maximum dry density of the control mixture and the mixtures containing recycled aggregates. As can be seen, the maximum dry density of the mixtures decreases with increasing the percentage of the recycled aggregates in the mixtures, which is attributed to the lower density of the coarse and fine recycled particles than that of the control mixture. The results also show that the maximum dry density of the mixtures containing recycled asphalt concrete are slightly higher than those of the mixtures containing recycled cement concrete, which is due to the lower density of the recycled cement concrete than that of the recycled asphalt concrete and also less resistance of the recycled asphalt concrete aggregate against compaction due to their more smooth surface. Fig. 8 shows the optimum compaction moisture content of the mixtures. As can be seen, the optimum moisture content increases and decreases, respectively, with increasing the recycled cement and asphalt concrete aggregate in the mixture. The increase 
of the moisture content with the increasing of the recycled cement concrete is due to the rougher surface and more moisture absorption of the particles. The recycled asphalt concrete has lower moisture absorption, and due to the lower friction between the particles, they need less water for compaction.

TABLE V: SOUNDNESS TEST RESULTS

\begin{tabular}{|c|c|c|c|c|}
\hline \multirow{2}{*}{ Mixtures } & \multicolumn{2}{|c|}{$\begin{array}{c}\text { Sodium Sulfate soundness test } \\
\text { results \% }\end{array}$} & \multicolumn{2}{c|}{$\begin{array}{c}\text { Freezing and thawing soundness } \\
\text { test results \% }\end{array}$} \\
\cline { 2 - 5 } & Fine & Coarse & Fines & Coarse \\
\hline B100 & 1.55 & 0.6 & 0.55 & 0.46 \\
\hline B80-C20 & 1.15 & 0.51 & 1.725 & 0.22 \\
\hline B50-C50 & 0.97 & 0.48 & 0.75 & 0.41 \\
\hline B25-C75 & 0.93 & 0.61 & 0.97 & 0.555 \\
\hline B80-A20 & 1.2 & 0.57 & 1.3 & 0.45 \\
\hline B50-A50 & 1.745 & 0.43 & 0.895 & 0.63 \\
\hline B25-A75 & 1.33 & 0.55 & 2.45 & 0.54 \\
\hline
\end{tabular}

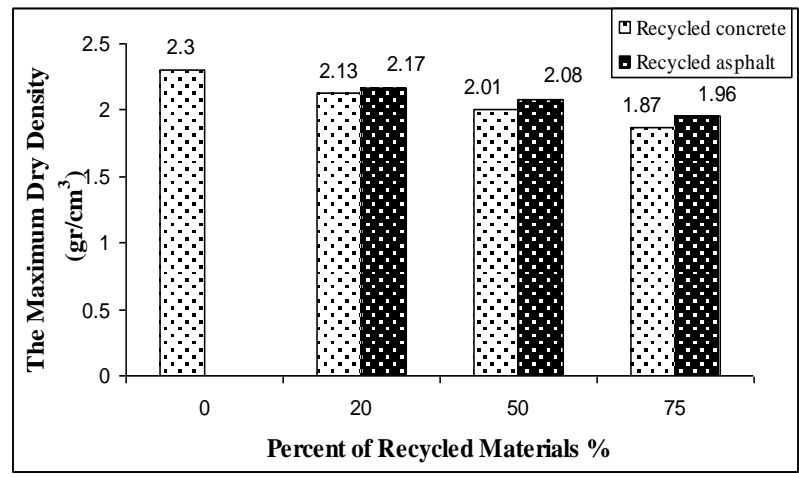

Fig. 7. The maximum dry density of the mixtures

\section{CONCLUSIONS}

In this research, different portions of natural aggregates of unbound base were replaced with recycled asphalt and cement concrete aggregate and some physical and mechanical properties of the mixtures were evaluated. For the materials used in this research and over the range of the variables value investigated, the following results can be drawn from this study:

- Direct application of crushed and graded waste asphalt and Portland cement concrete in unbound base results in reduction of sand equivalent. Therefore, it is recommended that the recycled aggregate be washed prior to using in unbound base.

- Recycled asphalt and cement concrete aggregates have lower toughness than the natural aggregates, which may lead to the increasing of fines during the performance of the unbound base. However, as long as they satisfy the requirement of the specification, they can be used in this application. In this research, the inclusion of recycled aggregate in the unbound base satisfies the maximum percent loss in Los Angeles test of 40.

- Inclusion of recycled asphalt and cement concrete in unbound base results in a reduction in bulk density, which decreases the transportation cost. In addition, water absorption of the mixtures containing recycled Portland cement and asphalt concrete is, respectively, higher and lower than the primary conventional aggregate.

- The unbound aggregate containing recycled asphalt and cement concrete meet the requirement of soundness for the application in base layer.

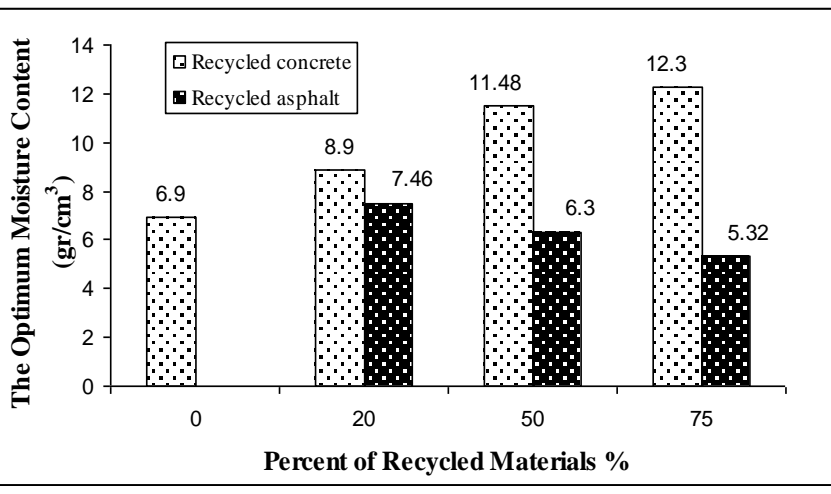

Fig. 8. The optimum moisture content of the mixtures

- The maximum dry density of the unbound base decreases with increasing the recycled aggregate content.

- The optimum moisture content of the unbound aggregate increases and decreases, respectively, with increasing the recycled Portland cement and asphalt concrete.

- Inclusion of recycled asphalt concrete in unbound base makes the mixture sensitive to compaction level, indicating that more control is required during the compaction operation of such materials.

\section{REFERENCES}

[1] N. D. Oikonomou, Recycled Concrete Aggregates, Cement and Concrete Composites, vol. 27, pp. 315-318, 2005.

[2] R. Schulz and F. Hendricks, "Recycling of masonry rubble. Recycling of demolished concrete and masonry," in Report of Technical Committee-Demolition and Reuse of Concrete, T. C. Hansen, Ed. London: RILEM, 1992, vol. 37.

[3] K. Frondistion and S. Yannas, "Economics of concrete recycling in the United States," Advanced Research Institute Problems in the Recycling Concrete, France, 1980.

[4] R. J. Collins, "Reuse of demolition materials in relation to specifications in the UK. Demolition and reuse of concrete and masonry: Guidelines for demolition and reuse of concrete and masonry," in Proc. the Third International RILEM Symposium on Demolition and Reuse of Concrete Masonry, Odense, Denmark, 1994, pp. 49-56.

[5] F. Agrela, A. Ramirez, A. Barbrado, and A. P. Galvin, "Real application of cement treated mixed recycled aggregates on road based in Malaga," presented at Transportation Research Board Annual Meeting, 2012.

[6] B. Huang, X. Shu, and E. G. Burdette, "Mechanical properties of concrete containing recycled asphalt pavements," Magazine of Concrete Research, vol. 58, no. 5, pp. 313-320, 2006.

[7] B. Huang, X. Shu, and G. Li, "Laboratory investigation of Portland cement concrete containing recycled asphalt pavements," Cement and Concrete Research, vol. 35, no. 10, pp. 2008-2013, May 2005.

[8] A. A. A. Molenaar and A. A. Van Niekerk, "Effects of gradation, composition, and degree of compaction on the mechanical 
characteristics of recycled unbound materials," Transportation Research Record, no. 1787, pp. 73-82, 2002.

[9] R. A. Macarthy, "General report: waste alternative materials, unbound aggregates in road construction," in Proc. the $3^{\text {rd }}$ International Simposium on Unbound Aggregates in Roads (UNBAR 3), Nottingham, United Kingdom, 11-13 June, 1989.

[10] A. A. A. Molenaar, D. X. Xuan, L. J. M. Houben, and Z. Shui, "Prediction of the mechanical characteristics of cement treated demolition waste for road bases and subbases," in Proc. $10^{t h}$ Conference on Asphalt Pavements for Southern Africa, KwaZuluNatal, South Africa, 2011.

[11] C. S. Poon and D. Chan, "Feasible use of recycled concrete aggregates and crushed clay brick as unbound road sub-base," Construction and Building Materials, vol. 20, pp. 578-585, 2005.

[12] D. X. Xuan, L. J. M. Hoube, A. A. A. Molenaar, and Z. Shui, "Investigation of combined effect of mixture variables on mechanica properties of cement treated demolition waste," Engineering Journal, vol. 16, no. 4, pp. 107-116, 2012.

[13] H. Taherkhani and B. Amani, "An investigation on the using of cement stabilized recycled concrete and brick in pavement layers," Indian Journal of Scientific Research, vol. 1, issue 2, pp. 297-306, 2014.

[14] H. Taherkhani and F. Farokhi, "Mechanical properties of cement stabilized mixtures of recycled asphalt and cement concrete for use in pavement," Indian Journal of Scientific Research, vol. 1, issue 2, pp. 288-296, 2014

[15] M. M. O’Mahony and G. W. E. Milligan, "Use of recycled materials in sub-base layers," Transport Res Record, vol. 1310, pp. 73-80, 1991.

[16] T. Bennert, W. J. Papp Jr, A. Maher, and N. Gucunski, "Utilization of construction and demolition debris under traffic-type loading in base and sub-base applications," Transport Res Record, vol. 1714, pp. 33 39, 2002.

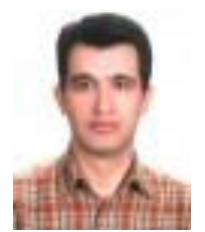

Hasan Taherkhani has received his PhD degree in civil engineering from the Nottingham University in 2006, after receiving his bachelor degree in civil engineering from the Iranian University of Science and Technology in 1992 and master degree in highway and transportation engineering in 1995 from the Tarbiat Modares University in Iran. He has been working as an assistant professor in Civil Engineering Department of University of Zanjan since 2006, and works in the field of experimental investigation of pavement materials, mostly on the application of solid wastes in the highway construction. 